\section{The Woven EndoBridge Finally Coming Home across the Atlantic: What to Expect?}

\author{
(D)W.J. van Rooij, (DS.B.T. van Rooij, DH.G. Kortman, \\ and (D).P. Peluso
}

T he Woven EndoBridge (WEB; Sequent Medical, Aliso Viejo, California) is an intrasaccular flow diverter primarily developed for wide-neck bifurcation aneurysms without the need for supporting stents and concomitant dual-antiplatelet therapy. The WEB consists of a self-expanding, oblong or spheric braid of platinum-cored nitinol wires intended to implant inside the aneurysmal sac, and it can be electrothermally detached. Since its introduction in 2010, the WEB has evolved from a high-profile dual-layer to a low-profile single-layer construction that can be delivered through a 0.017 -inch microcatheter in sizes up to 7 $\mathrm{mm} .{ }^{1}$ To date, more than $6000 \mathrm{WEBs}$ have been implanted worldwide, most of these in Europe.

In the United States, FDA approval is expected soon, and our American colleagues will then have an exciting new tool available for endovascular treatment of intracranial aneurysms. The extensive European experience with the WEB provides for a flying start in the United States.

In this article, we share our personal experience with the WEB after having treated almost 300 aneurysms with the device.

\section{How Did We Start?}

In 2014, we evaluated our results of stent-assisted coiling and found that stent placement in 45 patients with acutely ruptured aneurysms resulted in permanent neurologic deficit or death in 10 (22\%), in 5 due to thromboembolic complications and in 5 due to early rebleed in the postoperative period despite the aneurysms being adequately coiled. ${ }^{2}$ In February 2015, we considered an alternative for stent-assisted coiling in the new-generation WEB with a single layer, suitable for a 0.021 -inch microcatheter. We started to use the WEB in wide-neck unruptured aneurysms without supporting stents or balloons, and our first results were encouraging. To further master the technique of the WEB, we gradually expanded the indication to all aneurysms suitable for the WEB; in general, small aneurysms from 3 to $10 \mathrm{~mm}$, regardless of neck size or location. ${ }^{3-5}$

The Figure is a graphic display of the use of the WEB, coils, additional supporting devices, and flow diverters for endovascu-

Received June 1, 2018; Accepted June 27.

From the Department of Radiology (W.J.v.R., H.G.K., J.P.P.), Elisabeth Tweesteden Ziekenhuis, Tilburg, The Netherlands; and Department of Radiology (S.B.T.v.R.) Noordwest Ziekenhuisgroep, Alkmaar, The Netherlands.

Please address correspondence to W.J. van Rooij, MD, PhD, Department of Radiology, Elisabeth Tweesteden Ziekenhuis, Hilvarenbeekseweg 60, 5022GC Tilburg, The Netherlands; e-mail: wjjvanrooij@gmail.com

= Indicates article with supplemental on-line Appendix

http://dx.doi.org/10.3174/ajnr.A5798 lar treatment of intracranial aneurysms in our practice during 2013-2017.

\section{Access and Periprocedural Anticoagulation}

We use a biaxial approach with a short $(11 \mathrm{~cm}) 6 \mathrm{~F}$ sheath and a Benchmark (Penumbra, Alameda, California) guiding catheter positioned in the petrous carotid artery or V3 segment of the vertebral artery. Only with very tortuous vessels do we use a 90$\mathrm{cm}$-long sheath (Neuron Max; Penumbra) with a 6F or 5F distalaccess guiding catheter.

In our hospital (St Elisabeth Hospital Tilburg, The Netherlands), all admitted patients receive subcutaneous heparin, 2500 $\mathrm{U}$ twice daily, as a thrombotic prophylaxis. In patients with ruptured aneurysms, we use no other anticoagulation than heparin in the pressure bags for flushing ( $5000 \mathrm{U} / \mathrm{L})$. In patients with unruptured aneurysms, heparin, a $2500-5000 \mathrm{U}$ bolus, is given at the beginning of the procedure. Antiplatelet medication is not routinely administered.

In case of a thromboembolic complication, we try to remove the thrombus with thrombosuction or a stent retriever, and for peripheral emboli, tirofiban is used. When antiplatelet medication is considered necessary, aspirin, $500 \mathrm{mg}$, is given intravenously, later followed by prasugrel or clopidogrel (Plavix).

\section{WEB Sizing and Technique of Implantation}

The aneurysm is measured from $3 \mathrm{D}$ rotational images. Oversizing the WEB is imperative to assure anchoring the device to the aneurysm walls. In general, the WEB is oversized by $1-2 \mathrm{~mm}$ from the mean width of the aneurysm in 2 perpendicular planes. Because compression in the diameter results in increased height, the height is chosen 1-2 mm less than the actual aneurysm height. In regularly shaped aneurysms, WEB sizing is straightforward. In irregularly shaped aneurysms, some spatial awareness is helpful. Throughout our experience with WEB sizing, our sizing failure rate is about $25 \%$, which has not improved with time.

In the sizes of 4-7 mm, there is overlap between the WEB 21 and 17 systems. In general, the WEB 17 performs better in tortuous and difficult anatomy and the WEB 21 is more stable. Our personal preference is WEB 17 in the smallest sizes, $3-4 \mathrm{~mm}$, and WEB 21 in the larger sizes, 5-8 $\mathrm{mm}$.

The VIA 17 and 21 Microcatheters (Sequent Medical) are specifically developed for the WEB. These catheters can be steamshaped when necessary (about 1 in 10 in our practice) and are stable during WEB delivery. The technique of WEB implantation is as follows: The tip of the microcatheter is positioned in the dome of the aneurysm. Then, the first part of the WEB is slowly unsheathed by microcatheter withdrawal until half of the WEB is deployed. At that point, the WEB has become soft, and puncture of the aneurysm wall with the distal marker has become highly unlikely. Next, the microcatheter is slightly pushed forward to ensure that the WEB is in the fundus of the aneurysm. At this point, the WEB can be completely deployed by further retracting the microcatheter while keeping the WEB in place.

The position of the WEB is checked with an angiographic run. Sometimes a rotational angiographic run may be helpful to eval- 


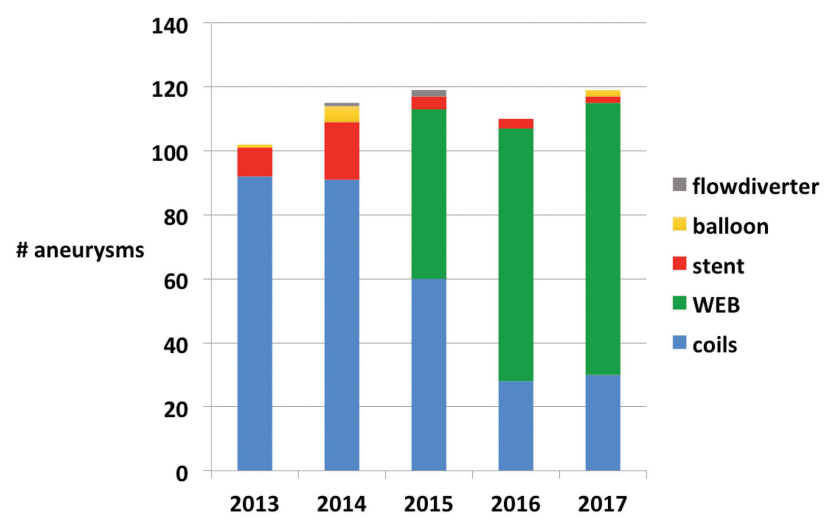

FIGURE. Evolution of devices used for endovascular treatment of intracranial aneurysms between 2013 and 2017.

uate the WEB position in relation to the aneurysm neck and parent vessels. We never use VasoCT (Philips Healthcare, Best, the Netherlands) for this purpose because this is time-consuming and we are somewhat afraid to recapture the WEB after several minutes have passed; possible thrombus formed inside the WEB may be fragmented and dispersed.

When a good WEB position is confirmed, the device is detached and the procedure is terminated, despite the possible presence of some flow inside the WEB and aneurysm.

The Appendix contains several links to videos of WEB treatments of intracranial aneurysms.

\section{Use of Additional Devices}

Additional coils are only rarely necessary to occlude the aneurysm or part of it. In most irregularly shaped aneurysms, the WEB can be used to cork the neck. Parts of the aneurysm not covered with the WEB will then thrombose anyway.

We never use a supporting balloon during WEB placement. In 2 cases with previously treated aneurysms, a stent was placed as a bailout procedure to stabilize the WEB after it tilted on detachment.

\section{Imaging Follow-Up after WEB Treatment}

Because many aneurysms still show some filling immediately after WEB placement, initial occlusion rates, as with coiling, cannot be given. We perform angiography after 3 months to confirm the absence of residual filling inside the WEB. Further follow-up is scheduled with 3T MRA. ${ }^{6}$ Because the WEB acts like a Faraday cage, possible residual flow may remain undetected. Fortunately, residual flow at 3 months is extremely rare; we encountered only a few cases in larger aneurysms.

\section{Additional Applications of the WEB}

The WEB can also be applied for parent vessel occlusion of both large and small arteries. ${ }^{7}$ For ICA occlusion, 2 WEBs are sufficient to occlude the artery. As opposed to detachable balloons, the WEB can be placed exactly in the desired position in the parent artery without fear of premature detachment. We maximally oversize the WEB in larger arteries such as the ICA or V4. The occlusion of small vessels such as the PICA (distal flow aneurysm) or the distal posterior cerebral artery (dissecting aneurysm) can be performed with the smallest WEB 17 devices.
The WEB can also be used in previously treated aneurysms. ${ }^{8}$ In wide-neck remnants, stents can be avoided. In large and giant partially thrombosed aneurysms, results with the WEB are as poor as with other techniques; the WEB will migrate into intraluminal thrombus just like coil meshes do.

\section{Clinical and Imaging Results and Implications for Practice}

Our published results with the WEB, both for ruptured and unruptured aneurysms, are good with a reopening/retreatment rate of $7 \%$, about $95 \%$ adequate occlusion, and no bleeds or rebleeds during follow-up. We encountered only 1 procedural rupture without clinical sequelae. Most thromboembolic complications were due to catheterization and not to the WEB..$^{1,3-5,7}$

Clinical results in our practice have improved since the WEB replaced stent-assisted coiling, especially in ruptured aneurysms. ${ }^{2,4}$ The simple periprocedural anticoagulation protocol without antiplatelet medication is a great advantage.

The WEB procedure is a single-catheter treatment and is usually straightforward and quick. After gradually gaining confidence with the WEB, we now treat most aneurysms (about 70\%) with this device (Figure). Only large aneurysms and shallow aneurysms are treated otherwise. In our practice, stents and flow diverters are never used in ruptured aneurysms and only rarely in unruptured aneurysms (Figure).

Although the use of the WEB has some technical issues, these can readily be learned by anyone with some experience with endovascular aneurysm treatment. The procedure is similar to simple coiling. Proper training on phantoms and proctoring of first cases can essentially avoid a learning curve. We recommend that first-time users start with simple aneurysms rather than with complex wide-neck aneurysms. Simple aneurysms can be wide-neck as long as there is sufficient height to accommodate oversizing in width. With growing confidence, more challenging aneurysms can be treated, sometimes surprisingly easily.

\section{Improvements and Perspectives}

The development of the WEB is ongoing. More shallow sizes are being developed, and experiments are being performed with changes in the WEB shape; for example, a hybrid version between Single-Layer and Single-Layer Sphere. The larger WEB sizes, 9-11 $\mathrm{mm}$, may become available in lower profiles suitable for a 0.027 inch instead of a 0.033 -inch microcatheter.

To reduce the proportion of incorrect sizing of about 1 in 4 , an automated 3D software program would be a valuable tool.

The WEB is now marketed as an expensive device, comparable with the price of stent-assisted coiling. With growing popularity, prices are likely to drop.

In summary, in our practice, the WEB has rapidly gained popularity and largely replaced the use of coils, stents, and flow diverters. The avoidance of dual antiplatelet medication is a great advantage over stents and flow diverters, resulting in fewer thromboembolic complications and fewer early rebleeds. The easy, quick, and safe technique has a convincing advantage over balloon- or stent-assisted coil treatments.

AJNR Am J Neuroradiol 39:1964-66 Nov 2018 www.ajnr.org 
Disclosures: Willem Jan van Rooij—RELATED: Consulting Fee or Honorarium: Terumo, MicroVention; Other: Terumo, MicroVention, Comments: Proctoring WEB cases. * Sanne van Rooij—RELATED: Grants: Noordwest Ziekenhuisgroep Alkmaar, and unrestricted grant from MicroVention; Comments: $20 \%$ of resident salary during 2 years. * Jo P. Peluso- RELATED: Consultancy: Proctoring WEB cases. * *Money paid to individual.

\section{REFERENCES}

1. van Rooij SB, Peluso JP, Sluzewski M, et al. The new low-profile WEB 17 system for treatment of intracranial aneurysms: first clinical experiences. AJNR Am J Neuroradiol 2018;39:859-63 CrossRef Medline

2. Bechan RS, Sprengers ME, Majoie CB, et al. Stent-assisted coil embolization of intracranial aneurysms: complication in acutely ruptured versus unruptured aneurysms. AJNR Am J Neuroradiol 2016;37: 502-07 CrossRef Medline

3. van Rooij WJ, Peluso JP, Bechan RS, et al. WEB treatment of ruptured intracranial aneurysms. AJNR Am J Neuroradiol 2016;37:1679-83 CrossRef Medline
4. van Rooij SB, van Rooij WJ, Peluso JP, et al. WEB treatment of ruptured intracranial aneurysms: a single center cohort of 100 patients. AJNR Am J Neuroradiol 2017;38:2282-87 CrossRef Medline

5. van Rooij SB, van Rooij WJ, Peluso JP, et al. The Woven EndoBridge (WEB) as primary treatment for unruptured intracranial aneurysms. Interv Neuroradiol 2018 Jan 1. [Epub ahead of print] CrossRef Medline

6. van Rooij S, Peluso JP, Sluzewski M, et al. Mid-term 3T-MRA follow-up of intracranial aneurysms treated with the Woven EndoBridge (WEB). Interv Neuroradiol 2018 Jan 1. [Epub ahead of print] CrossRef Medline

7. van Rooij WJ, Sluzewski M, Bechan RS, et al. Therapeutic internal carotid or vertebral artery occlusion using the WEB device. Interv Neuroradiol 2016;22:365-67 CrossRef Medline

8. van Rooij SB, van Rooij WJ, Sluzewski, M et al. The Woven EndoBridge (WEB) for recurrent aneurysms: clinical and imaging results. Interv Neuroradiol 2018 Sep 12 [Epub ahead of print] 